\section{The hologenome theory disregards the coral holobiont}

\author{
William Leggat ${ }^{* *}$, Tracy Ainsworth ${ }^{*}$, John Bythell", Sophie Dove ${ }^{\star s}$, \\ Ruth Gates $₫$, Ove Hoegh-Guldberg ${ }^{\star s}$, Roberto Iglesias-Prieto ${ }^{\#}$ and \\ David Yellowlees**
}

The 'hologenome theory of evolution', proposed by Rosenberg and colleagues ${ }^{1}$, suggests that reef corals, and by extrapolation other multicellular organisms, adapt to environmental stress by alterations in their resident microbial communities. Although this is an interesting idea, we strongly disagree with aspects of this theory, specifically those that arise from the omission and flawed interpretation of the coral literature (for reviews of omitted literature see REFS 2,3).

The theory is based on the author's observation that Oculina patagonica bleaches in response to Vibrio shiloi infection and it was subsequently suggested that all coral bleaching is the result of bacterial infection ${ }^{1,4}$. Our main criticism of this hypothesis is that bleaching is a broad stress response in corals, which has been observed even in the absence of the proposed bacterial causal agents ${ }^{1}$. In fact, there is no experimental evidence to support a role for bacteria in the mass coral-bleaching events that occur over large geographical scales. The bulk of the literature indicates a direct link

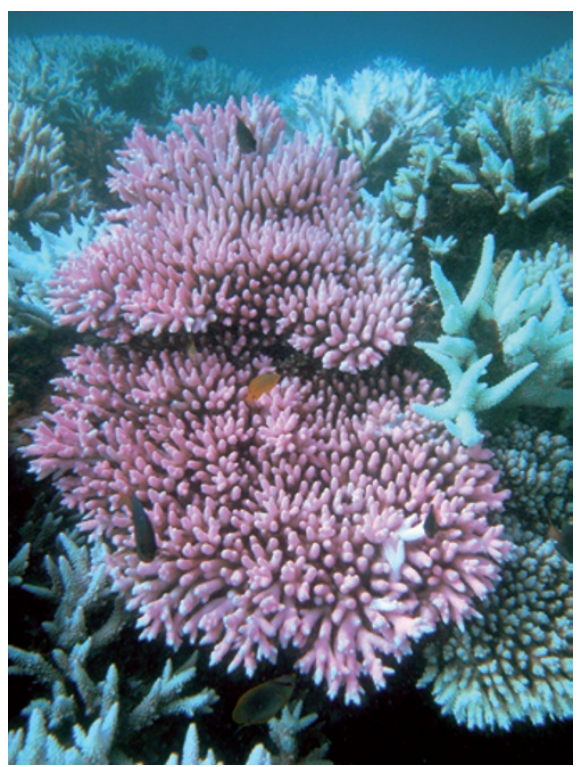

Figure $1 \mid$ A mass bleaching event on the Great Barrier Reef in 2006. These events simultaneously affect multiple species over large geographial ranges and are highly correlated with elevated seawater temperatures. between mass bleaching and the anomalous temperatures that disrupt photosynthesis in the endosymbiotic dinoflagellates that are harboured by corals $s^{5-8}$; this is analogous to the bleaching that occurs in higher plants ${ }^{9}$. However, this overwhelming evidence was completely ignored by Rosenberg and colleagues. In addition, studies from both terrestrial and marine environments have demonstrated that there is increased disease prevalence and severity in stressed populations ${ }^{10}$, which suggests that a less-fit holobiont has emerged. These observations completely contradict the expected outcomes of the hologenome theory.

Rosenberg and colleagues also over-simplify the highly complex relationship between host and symbiont, and make broad assumptions about coral and invertebrate immunity. For example, they fail to acknowledge the molecular diversity of the endosymbiotic dinoflagellates and the array of responses and adaptive mechanisms that this union provides the holobiont. They also ignore a range of studies that clearly demonstrate the presence of highly conserved acclimatization mechanisms, which are mobilized to accommodate changes in the environment in both coral and endosymbiotic dinoflagellates. These include the induction of heat-shock proteins and antioxidant enzymes, restructuring of the light-harvesting complexes and differential expression of host pigmentation (reviewed in REF. 11). In addition, the authors imply that invertebrates lack immune memory, which is a feature of acquired immunity in vertebrates. A range of recent studies (reviewed in REFS 12,13) have demonstrated the presence of immune memory in invertebrates. Further, a recent survey of available cnidarian genome information shows that Toll and Toll-likereceptor homologues ${ }^{14}$ are present, which strongly suggests that a pathway for immune memory exists in corals.

In conclusion, Rosenberg and colleagues present a hypothesis that is based on a small subset of the available coral and bleaching literature, and have dismissed without comment well-established facts about endosymbiosis and the host. Their microbial-centric view is at odds with the now widely embraced coral holobiont model ${ }^{15}$. We feel that the lack of consideration of the wide and diverse scientific literature on coral bleaching, coupled with the absence of scientific evidence that supports a role for bacterial populations in driving global patterns of bleaching, combine to raise serious questions as to the relevance of the hologenome theory of evolution.

*ARC Centre of Excellence for Coral Reef Studies, James Cook University, Townsville, Queensland 4811

Australia.

${ }^{\ddagger}$ School of Pharmacy and Molecular Sciences, James Cook University, Townsville, Queensland 4811,

Australia.

${ }^{\S}$ Centre for Marine Studies, University of Queensland, Brisbane 4072, Australia

School of Biology, Newcastle University, Newcastle upon Tyne NE1 7RU, UK.

'University of Hawaii, School of Ocean and Earth Science and Technology, Hawaii Institute of Marine Biology, Kaneohe HI96744, USA.

\#Universidad Nacional Autónoma de México, Apartado Postal 1152, Cancún 77500, Mexico.

Correspondence to W.L. e-mail: bill.leggat@jcu.edu.au

doi: 10.1038/nrmicro $1635 \mathrm{C} 1$

Rosenberg, E., Koren, O., Reshef, L., Efrony, R. \& Zilber-Rosenberg, I. The role of microorganisms in coral health, disease and evolution. Nature Rev. Microbiol. 5, 355-362 (2007).

Hoegh-Guldberg, O. Coral reefs in a century of rapid environmental change. Symbiosis 37, 1-31 (2004). Douglas, A. E. Coral bleaching - how and why? Mar. Pollut. Bull. 46, 385-392 (2003)

Reshef, L., Koren, O., Loya, Y., Zilber-Rosenberg, I. \& Rosenberg, E. The coral probiotic hypothesis. Environ. Microbiol. 8, 2068-2073 (2006).

Iglesias-Prieto, R., Matta, J. L., Robins, W. A. \& Trench, R. K. Photosynthetic response to elevated temperature in the symbiotic dinoflagellate

Symbiodinium microadriaticum in culture. Proc. Natl Acad. Sci. USA 89, 10302-10305 (1992).

6. Warner, M. E., Fitt, W. K. \& Schmidt, G. W. Damage to photosystem II in symbiotic dinoflagellates: a determinant of coral bleaching. Proc. Natl Acad. Sci. USA 96, 8007-8012 (1999).

Jones, R. J., Hoegh-Guldberg, O., Larkum, A. W. D. \& Schreiber, U. Temperature-induced bleaching of corals begins with impairment of the $\mathrm{CO}_{2}$ fixation mechanism in zooxanthellae. Plant Cell Environ. 21, 1219-1230 (1998).

8. Tchernov, D. et al. Membrane lipids of symbiotic algae are diagnostic of sensitivity to thermal bleaching in corals. Proc. Natl Acad. Sci. USA 101, 13531-13535 (2004).

9. Sharkey, T. D. Effects of moderate heat stress on photosynthesis: importance of thylakoid reactions, rubisco deactivation, reactive oxygen species, and thermotolerance provided by isoprene. Plant Cell Environ. 28, 269-277 (2005).

10. Harvell, C. D. et al. Climate warming and disease risks for terrestrial and marine biota. Science 296 2158-2162 (2002)

11. Coles, S. L. \& Brown, B. E. Coral bleaching-capacity for acclimatization and adaptation. Adv. Mar. Biol. 46, 183-223 (2003)

12. Kurtz, J. Specific memory within innate immune systems. Trends Immunol. 26, 186-192 (2005).

13. Little, T. J., Hultmark, D. \& Read, A. F. Invertebrate immunity and the limits of mechanistic immunology. Nature Immunol. 6, 651-654 (2005).

14. Miller, D. et al. The innate immune repertoire in Cnidaria - ancestral complexity and stochastic gene loss. Genome Biol. 8, R59 (2007).

5. Rohwer, F., Seguritan, V., Azam, F. \& Knowlton, N. Diversity and distribution of coral-associated bacteria. Mar. Ecol. Prog. Ser 243, 1-10 (2002). 